\title{
Unusual presentation of angiomyomatous hamartoma in an eight-month-old infant: case report and literature review
}

\author{
Vincenzo Davide Catania ${ }^{1}$, Carlo Manzoni ${ }^{1}$, Mariangela Novello ${ }^{2}$, Libero Lauriola ${ }^{2 *}$ and Antonella Coli
}

\begin{abstract}
Background: Evaluation of palpable neck masses may be a diagnostic problem in pediatric patients, with differential diagnosis including congenital, inflammatory, tumoral and traumatic lesions. Ultrasonography is usually a satisfactory method to make a correct pre-operative evaluation of neck masses, although diagnosis is often challenging for the surgeon and the radiologist and sometimes only possible after a histopathological examination of the resected lesion.

Case presentation: We report an 8-month-old patient with a cervical, anterior midline mass. Ultrasonographic images showed features suggesting a partly cystic lesion, with a preoperative suspect of thyroglossal duct cyst. Histological examination, performed after surgical removal of the mass, led to a diagnosis of lymph node angiomyomatous hamartoma (AH).
\end{abstract}

Conclusions: $\mathrm{AH}$, a rarely occurring benign lymph node lesion, has been reported in the neck lateral region only twice. This case, presenting as a palpable neck midline mass, is the first reported case occurring in infancy. Although rare, AH should be included in the differential diagnosis of head and neck masses.

Keywords: Angiomyomatous hamartoma, Pediatric neck mass, Ultrasonography, Lymph node

\section{Background}

Palpable neck masses are a common clinical concern in pediatric patients, and differential diagnosis includes a wide range of pathologies, such as congenital, inflammatory, tumoral and traumatic lesions. Malformative neck masses in childhood are branchial cleft cysts, ectopic thymus, teratomas, cystic lymphangioma, aberrant thyroid tissue and others [1-6]. Thyroglossal duct cyst is a congenital anomaly related to persistence of thyroglossal duct, presenting as a midline cyst, near the hyoid bone with variable sonographic appearances $[7,8]$. $\mathrm{AH}$ is a rare, benign lymph node pathology consisting of a fibrous transformation of the hilar region, also with presence of vessels and smooth muscle cell proliferation. Of 28 cases hitherto reported, only two were located in the lateral neck region, both in adult patients, and the lesion has been more frequently found in the inguinal and femoral region [9-11].

\footnotetext{
* Correspondence: llauriola@rm.unicatt.it

${ }^{2}$ Department of Anatomic Pathology, Catholic University of Sacred Heart, Largo A. Gemelli 8, Rome 00168, Italy

Full list of author information is available at the end of the article
}

Ultrasonography (US) is an accurate, cost-effective, non-invasive preoperative analysis, usually sufficient to make correct preoperative diagnoses, even if the accuracy of this imaging method may have limitations, because of the variability of the sonographic appearances $[12,13]$. Computed tomography and magnetic resonance imaging play a supplementary diagnostic role. Obviously, surgical excision with histological examination allows a definite diagnosis.

The authors herein describe an unusual case of $\mathrm{AH}$ presenting as a palpable mass in the anterior midline neck region of an infant. US preoperative evaluation of the lesion appeared compatible with a partly cystic mass, and, due to the peculiar location, a thyroglossal duct cyst was suspected or, secondly, a dermoid cyst, a small teratoma or an enlarged reactive lymph node.

\section{Case presentation}

An 8-month-old Philippine female baby without other health problems presented with a palpable neck mass of 4 months' duration. The patient did not suffer from 
dysphagia nor dysphonia. The past medical history was unremarkable. On physical examination, a midline anterior neck mass, tender and mobile when swallowing, contiguous to the hyoid bone was observed. No enlarged lymph nodes were detected in the lateral neck region. Laboratory values were in normal range. At US, a lesion largely hypoechoic measuring $20 \times 14 \mathrm{~mm}$ in diameter, with internal heterogeneous echoes, with a well defined periphery (Figure 1) was detected and the thyroid gland did not show abnormalities. A thyroglossal duct cyst was suspected and the patient underwent surgical excision. Intraoperatively we couldn't differentiate if the lesion was a solid mass or a cystic one and its malignant potential, if any, so that the Sistrunk procedure was chosen for safety's sake. A careful dissection of the lesion was performed, and the central portion of the hyoid bone was resected. In the postoperative course, the patient suffered from dyspnea and dysphonia, with relief of symptoms on the third post-operative day. At follow-up, 8 months after surgery, the patient was well, without evidence of disease.

On gross examination, the excised mass measured 20 $\mathrm{mm}$ in largest diameter; a central fibrous areas was detected, without evidence of cyst. The tissue was fixed in $10 \%$ buffered formalin, routinely processed and paraffin embedded. Histological examination revealed a preserved lymph node structure at the periphery, with reactive follicles and dilated sinuses, whereas, in the region of the hilum, the nodal parenchyma was completely replaced by a fibrous tissue (Figure 2) containing numerous irregular vessels and spindle cell bundles (Figure 3). On immunohistochemical analysis, the spindle cells

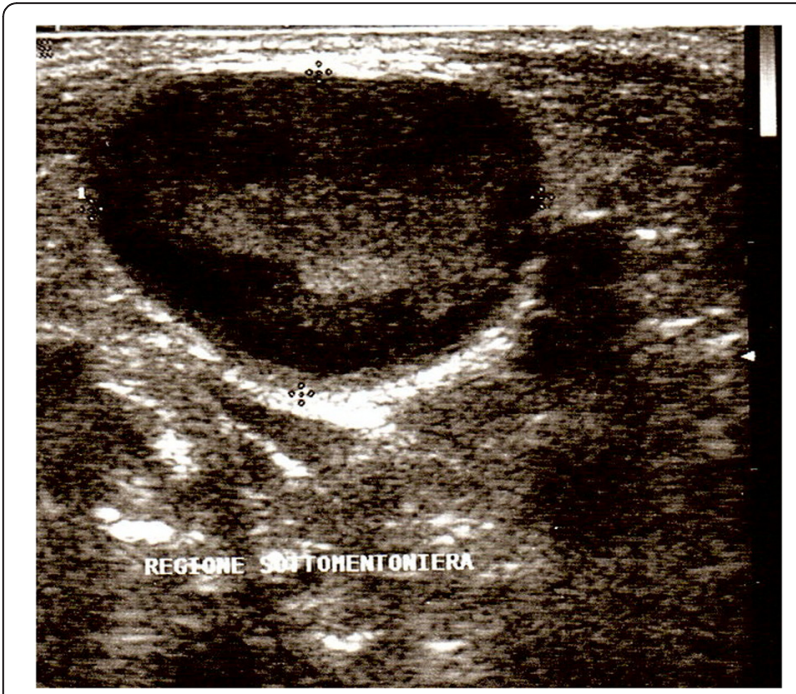

Figure 1 Ultrasonographic findings in an 8-month-old girl with a midline neck lesion. Sonogram shows a well-defined oval mass characterized by a hypoechoic peripheral layer and heterogeneous internal echoes.

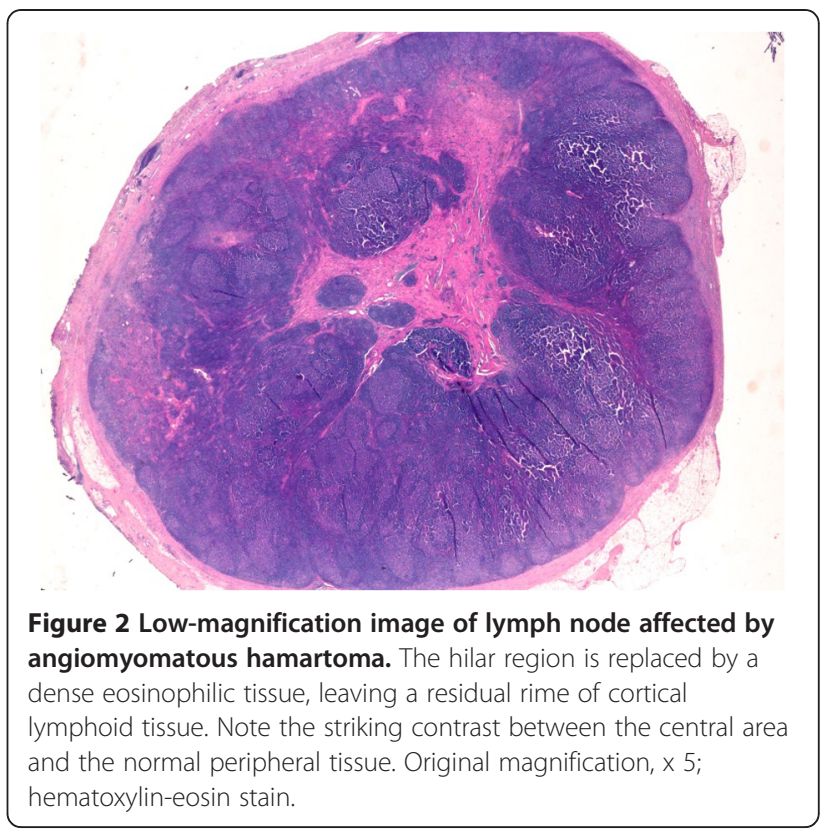

appeared as smooth muscle fibers, as confirmed by their positivity for HHF35 and desmin. Consecutive sections did not document presence of a cystic lesion. All the aforementioned findings were consistent with a pathological diagnosis of $\mathrm{AH}$ of the lymph node.

\section{Conclusions}

Neck lesions more commonly encountered in pediatric population consist of congenital, inflammatory or neoplastic diseases [3,5]. In addition to branchial cleft cysts, located in the lateral neck, malformative midline lesions prevalently belong to thyroglossal duct sinus and cyst, and present with a variable US appearance, ranging from a typical anechoic cyst to a pseudosolid lesion $[7,8]$.

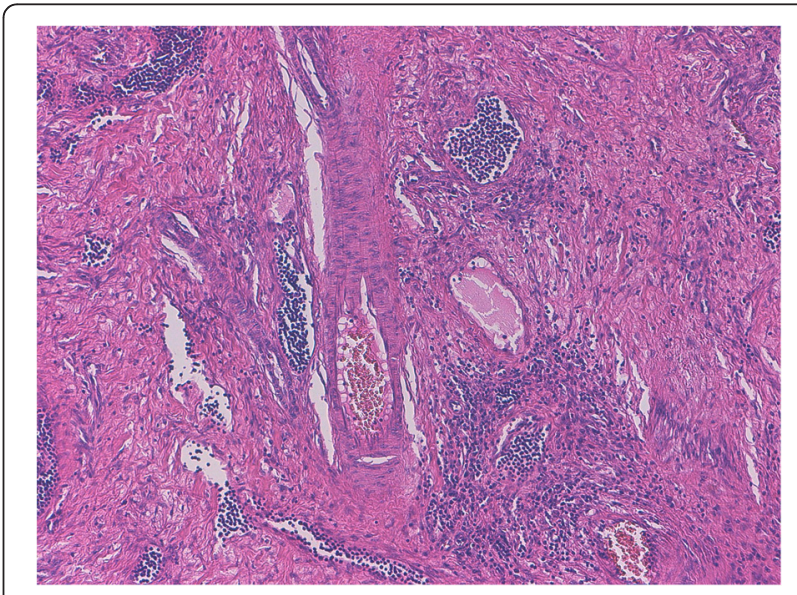

Figure 3 At higher magnification, the inner area of the lymph node shows irregular vessels and smooth muscle cells haphazardly interspersed throughout a collagenous stroma. Original magnification, x 100; hematoxylin-eosin stain. 
$\mathrm{AH}$ is a rare, benign form of lymph node hilar modification characterized by parenchymal replacement by fibrous tissue containing vessels and smooth-muscle proliferation. It prevalently involves inguinal lymph nodes, appearently starting in the hilum and extending towards the cortex. This entity was first described by Chan et al. in 1992, and, so far, 28 cases have been reported in the literature [9-11,14-23]. Table 1 shows age, gender and location of the lesion in 28 patients.

In our infant patient, $\mathrm{AH}$ occurred in a midline neck lymph node. To our knowledge, only two cases, both in adults, have been documented in the lateral neck region. The ultrasound image of the lump yielded a suspected cystic lesion, for the variable tissue density and for the presence of an internal fibro-vascular area contrasting with the intact lymph node periphery and providing the

Table 1 Cases of angiomyomatous hamartoma reported in literature

\begin{tabular}{|c|c|c|c|c|}
\hline Case $\mathrm{n}$. & Author, year ${ }^{\text {(ref) }}$ & Age (y) & Sex & Site \\
\hline \multirow[t]{12}{*}{$1-12$} & Chan et al., 1992 [9] & 80 & $M$ & $L$ inguinal \\
\hline & & 24 & M & $L$ inguinal \\
\hline & & 10 & $F$ & $L$ inguinal \\
\hline & & 19 & $M$ & $L$ inguinal \\
\hline & & 19 & $M$ & R inguinal \\
\hline & & 50 & $F$ & $L$ inguinal \\
\hline & & 31 & $M$ & $R$ inguinal \\
\hline & & 56 & $M$ & $R$ inguinal \\
\hline & & 60 & $M$ & $L$ inguinal \\
\hline & & 56 & $M$ & $L$ inguinal \\
\hline & & 52 & $M$ & $R$ inguinal \\
\hline & & 44 & $M$ & R femoral \\
\hline 13 & Allen et al., 1993 [14] & 67 & $F$ & R femoral \\
\hline 14 & Laeng et al., 1996 [10] & 17 & $\mathrm{~F}$ & L latero-cervical \\
\hline 15 & Magro et al., 1997 [15] & 68 & $M$ & $L$ inguinal \\
\hline 16 & Sakurai et al., 2000 [16] & 51 & $M$ & $R$ inguinal \\
\hline 17 & Dargent et al., 2004 [17] & 29 & $M$ & $R$ inguinal \\
\hline 18 & Piedimonte et al., 2006 [18] & 34 & $F$ & $L$ inguinal \\
\hline 19 & Sullu et al., 2006 [19] & 33 & $F$ & $R$ inguinal \\
\hline 20 & Mauro et al., 2008 [20] & 41 & M & L popliteal \\
\hline 21 & Barzilai et al., 2009 [11] & 51 & $\mathrm{~F}$ & L latero-cervical \\
\hline \multirow[t]{5}{*}{$22-26$} & Bourgeois et al., 2009 [21] & 8 & $M$ & $L$ inguinal \\
\hline & & 15 & $\mathrm{~F}$ & $L$ inguinal \\
\hline & & 30 & M & $\mathrm{R}$ inguinal \\
\hline & & 50 & $M$ & $L$ inguinal \\
\hline & & 57 & $M$ & $R$ inguinal \\
\hline 27 & Ram et al., 2009 [22] & 82 & M & $L$ inguinal \\
\hline 28 & Prusac et al., 2011 [23] & 14 & $M$ & R popliteal \\
\hline 29 & Present case & 8 months & $F$ & Midline cervical \\
\hline
\end{tabular}

hypothesis of thyroglossal duct cyst. The histological examination, performed after excision, allowed the correct diagnosis.

The pathogenesis of this lesion is unclear. A possible explanation is that $\mathrm{AH}$ represents a vascular and smooth muscle proliferative response to chronic impairment of nodal lymphatic flow or to previous nodal inflammation $[9,16]$.

Notwithstanding the rarity, $\mathrm{AH}$ should be included in the differential diagnosis of neck masses. The treatment of choice for this benign disease is surgical excision. The Sistrunk procedure, performed in our case, is a safe and successful technique with low complications.

\section{Consent}

Written informed consent was obtained from the parents for publication of this case report and any accompanying images.

\section{Competing interests}

The authors declare that they have no competing interests.

\section{Authors' contributions}

VDC and AC conceived the study and drafted the manuscript. VDC participated in surgery. LL has been involved in drafting and critical revision of the manuscript. CM did surgery and revised the manuscript. MN was involved in preparation of figures and manuscript revision. All authors read and approved the final manuscript.

\section{Author details}

'Department of Pediatric Surgery, Catholic University of Sacred Heart, Largo A.Gemelli 8, Rome 00168, Italy. ${ }^{2}$ Department of Anatomic Pathology, Catholic University of Sacred Heart, Largo A. Gemelli 8, Rome 00168, Italy.

Received: 17 June 2012 Accepted: 26 October 2012

Published: 6 November 2012

\section{References}

1. Hsieh YY, Hsueh S, Hsueh C, Lin JN, Luo CC, Lai JY, Huang CS: Pathological analysis of congenital cervical cysts in children: 20 years of experience at Chang Gung Memorial Hospital. Chang Gung Med J 2003, 26:107-113.

2. Turkyilmaz Z, Karabulut R, Bayazit YA, Sonmez K, Koybasioglu A, Yilmaz M, Kemaloglu YK, Basaklar AC: Congenital neck masses in children and their embryologic and clinical features. B-ENT 2008, 4:7-18.

3. Tracy TF Jr, Muratore CS: Management of common head and neck masses. Semin Pediatr Surg 2007, 16:3-13.

4. Osifo OD, Ugiagbe EE: Neck masses in children: etiopathology in a tertiary center. Niger J Clin Pract 2011, 14:232-236.

5. Telander RL, Filston HC: Review of head and neck lesions in infancy and childhood. Surg Clin North Am 1992, 72:1429-1447.

6. Turkington JR, Paterson A, Sweeney LE, Thornbury GD: Neck masses in children. Br J Radiol 2005, 78:75-85.

7. Wadsworth DT, Siegel MJ: Thyroglossal duct cyst: variability of sonographic findings. Am J Radiol 1994, 163:1475-1477.

8. Ahuja AT, King AD, Metreweli C: Sonographic evaluation of thyroglossal duct cysts in children. Clin Radiol 2000, 55:770-774.

9. Chan JKC, Frizzera G, Fletcher CDM, Rosai J: Primary vascular tumors of lymph nodes other than Kaposi's sarcoma. Analysis of 39 cases and delineation of two new entities. AJR Am J Roentgenol 1992, 16:335-350.

10. Laeng $\mathrm{RH}$, Hotz MA, Borisch $\mathrm{B}$ : Angiomyomatous hamartoma of a cervical lymph node combined with haemangiomatoids and vascular transformation of sinuses. Histopathology 1996, 29:80-84.

11. Barzilai G, Schindler $Y$, Cohen-Kerem R: Angiomyomatous hamartoma in a submandibular lymph node: a case report. Ear Nose Throat J 2009, 88:831-832 
12. Sidell DR, Shapiro NL: Diagnostic accuracy of ultrasonography for midline neck masses in children. Otolaryngol Head Neck Surg 2011, 144:431-434.

13. Friedman ER, John SD: Imaging of pediatric neck masses. Radiol Clin North Am 2011, 49:617-632.

14. Allen PW, Hoffman GJ: Fat in angiomyomatous hamartoma of lymph node. Am J Surg Pathol 1993, 17:748-749.

15. Magro G, Grasso S: Angiomyomatous hamartoma of the lymph node: case report with adipose tissue component. Gen Diagn Pathol 1997, 143:247-249.

16. Sakurai Y, Shoji M, Matsubara T, Imazu H, Hasegawa S, Ochiai M, Funabiki T, Mizoguchi Y, Kuroda M, Kasahara M: Angiomyomatous hamartoma and associated stromal lesions in the right inguinal lymph node: a case report. Pathol Int 2000, 50:655-659.

17. Dargent J-L, Lespagnard L, Verdebout J-M, Bourgeois P, Munck D: Glomeruloid microvascular proliferation in angiomyomatous hamartoma of the lymph node. Virchows Arch 2004, 445:320-322.

18. Piedimonte A, De Nictolis M, Lorenzini P, Sperti V, Bertani A: Angiomyomatous hamartoma of inguinal lymph nodes. Plast Reconstr Surg 2006, 117:714-716.

19. Süllü Y, Gün S, Dabak N, Karagöz F: Angiomyomatous hamartoma in the inguinal lymph node: a case report. Turk J Pathol 2006, 22:42-44.

20. Mauro CS, McGough RL III, Rao UNM: Angiomyomatous hamartoma of a popliteal lymph node: an unusual cause of posterior knee pain. Ann Diagn Pathol 2008, 12:372-374

21. Bourgeois P, Dargent J-L, Larsimont D, Munck D, Srales F, Boels M, De Valck C: Lymphoscintigraphy in angiomyomatous hamartomas and primary lower limb lymphedema. Clin Nucl Med 2009, 34:405-409.

22. Ram M, Alsanjari N, Ansari N: Angiomyomatous hamartoma: a rare case report with review of the literature. Rare Tumors 2009, 1:e25.

23. Prusac IK, Juric I, Lamovec J, Culic V: Angiomyomatous hamartoma of the popliteal lymph nodes in a patient with Klippel-Trenaunay syndrome: case report. Fetal Pediatr Pathol 2011, 30:320-324.

doi:10.1186/1471-2431-12-172

Cite this article as: Catania et al:: Unusual presentation of

angiomyomatous hamartoma in an eight-month-old infant: case report and literature review. BMC Pediatrics 2012 12:172.

\section{Submit your next manuscript to BioMed Central and take full advantage of:}

- Convenient online submission

- Thorough peer review

- No space constraints or color figure charges

- Immediate publication on acceptance

- Inclusion in PubMed, CAS, Scopus and Google Scholar

- Research which is freely available for redistribution 